\title{
Mandibular Subcondylar Fractures: A Review on Treatment Strategies
}

\author{
Mohammad Bayat ${ }^{1}$, Milad Parvin $^{2}$, Ali Aghaei Meybodi ${ }^{2}$
}

\begin{abstract}
${ }^{1}$ DMD, MS of Oral and Maxillofacial Surgery, Associate Professor, Department of Oral and Maxillofacial Surgery, Shariati General Hospital, Tehran University of Medical Sciences, Tehran, Iran

${ }^{2}$ DMD, Resident of Oral and Maxillofacial Surgery, Department of Oral and Maxillofacial Surgery, Shariati General Hospital, Tehran University of Medical Sciences, Tehran, Iran
\end{abstract}

\section{Type of article: Mini review}

\begin{abstract}
Condylar injuries are often subjected to discussion and controversy in maxillofacial surgery as they constitute many of the facial fractures. The condylar area has a great clinical value due to its important components. Vital components in this area are susceptible to functional disability due to either the fracture itself or the subsequent surgical intervention. Each of the strategies for the management of these fractures has its advantages and disadvantages. As there are controversies around management of condylar fractures, different treatment modalities are suggested in literature, so this paper reviews different treatment strategies of the following types of fractures in adults: 1-Closed reduction with maxillomandibular fixation, 2-Open reduction with internal fixation, 3-Endoscopic-assisted reduction with internal fixation. In conclusion, we declare that the endoscopic surgery is certainly a good replacement for approaches through the skin, for subcondylar fractures, but still more randomized clinical trials are needed to be carried out on this issue.

Keywords: Mandible condyle fractures, Closed reduction, ORIF, Endoscopic assisted, Maxillomandibular fixation
\end{abstract}

\section{Introduction}

Condylar injuries are often a matter of discussion and controversy among maxillofacial topics (1). These traumas constitute $11-16 \%$ of all facial fractures (2-5) and 30-40\% of mandibular fractures (3-7). Anatomically, the subcondylar area is the distal part of the condylar process. This area is superiorly confined to the line passing through the sigmoid notch and anteriorly to the line obliquely connecting the sigmoid notch to the masseter tuberosity (8). This area has a great clinical value due to important components such as the facial nerve and temporomandibular joint (TMJ). Both of these are prone to functional disability due to either the fracture itself, or the surgical intervention. Different stages of dislocation, displacement, comminution and fracture line are dependent on the force magnitude, point of application and transmission, and the patient's mandibular position and occlusion, during the trauma (8). One of the reasons that cause condylar fractures to be of paramount importance in maxillofacial surgery, is that many ensuing complications are connected to a condylar fracture, whether it is treated or not. Even though early clinical results are seen to be good, complications such as pain, restriction of movement, muscle spasms, mandibular deviation, malocclusion, pathologic alterations of the TMJ, osteonecrosis, facial asymmetry, and ankylosis may be evident later (9-13). Other complications related to the condylar fracture are ranged from tympanic bone fracture, fracture of mandibular fossa of temporal bone with or without dislocation of the condylar segment into the middle cranial fossa, injury to the cranial nerves, vascular damage and bleeding, growth inhibition and arteriovenous fistula $(14,15)$. As there are controversies around management of condylar fractures, different treatment modalities are suggested in literature (16). The aim of this study was to review the different treatment strategies of these fractures in adults:

1) Closed reduction with maxillomandibular fixation (MMF)

\section{Corresponding author:}

Dr. Ali Aghaei Meybodi, Department of Oral and Maxillofacial Surgery, Shariati General Hospital, Tehran University of Medical Sciences, Tehran, Iran. Tel: +98.9151244668, Email: meybodi777@yahoo.com

Received: May 06, 2016, Accepted: July 12, 2016, Published: October 2016 iThenticate screening: July 12, 2016, English editing: August 26, 2016, Quality control: September 03, 2016

(C) 2016 The Authors. This is an open access article under the terms of the Creative Commons Attribution-NonCommercialNoDerivs License, which permits use and distribution in any medium, provided the original work is properly cited, the use is non-commercial and no modifications or adaptations are made. 
2) Open reduction with internal fixation (ORIF)

3) Endoscopic-assisted reduction with internal fixation (ERIF)

\section{Discussion}

\subsection{Closed reduction with maxillomandibular fixation}

Closed reduction was historically considered the standard treatment for subcondylar fractures (17). The assumption that a closed reduction will result in fewer complications, though the esthetics and functionality will be just the same as an ORIF treatment, induced this method as the common procedure. The noninvasive nature of this method will consequently result in a very little to no facial nerve damage or scaring (18). Despite this knowledge, and much debating, authors are still unable to agree on an absolute treatment plan for management of condylar fractures. Some publications, state no marked difference between the results of open or closed treatments (16, 19-21). Closed treatment however, is considered undesirable in some other studies $(17,22,23)$. Unfortunately no clinical trial large enough is available on this matter to answer these questions. Duration of MMF is another matter of conflict for the closed reduction approach. It is mentioned in different articles that duration of MMF has a range of two to six weeks (8). The shortest time for MMF is chosen by surgeons, to avoid possible ankylosis of the temporomandibular joint (24). The precise reason for the ankylosis is yet to be explained but in theory, the bleeding in the joint, hematoma and the following fibrosis and bone generation due to a trauma, could cause the undesired ankylosis $(25,26)$. It would thus be wise to assume that TMJ ankylosis is a result of a direct trauma to the joint capsule or condylar head therefore the risk of ankylosis is minor in subcondylar fractures: hence, longer periods of MMF should be considered for a better union in fractures distant from the joint capsule (8). Upon conclusion of the gathered information, the authors suggest 4-6 weeks of MMF in the subcondylar fractures in which the TMJ capsule is not involved. This protocol is also applicable to bilateral fractures in which the fractured segments are not displaced. However in bilateral fractures, segments are more prevalently prone to displacement, thus an ORIF approach is recommended.

\subsection{Open reduction and internal fixation}

Since the introduction of internal fixation appliances, open reduction of condylar fractures is becoming more popular. Few studies emphasize on the indications of this treatment procedure (27), but as a general rule, the need for anatomic reduction in complex fractures is one reason to employ the open reduction and internal fixation approach. Nowadays, many of the upcoming articles are discussing the better results of the surgical treatment of the condylar fractures, for better occlusion, bone morphology and TMJ function (20, 28-31). Others however argue that a surgical access to the mandibular condyle, would increase the risk of trauma to the facial nerve and leave unpleasant scaring $(27,32-34)$. Hypertrophic scaring in $7.5 \%$ of cases are said to be quite tangible and significant (27). However the superior anatomic reduction and better functional results, induce ORIF as the treatment of choice in patients with complex conditions. Another advantage would be the immediate capability of the patient to move the injured area, reducing the MMF required time and thus lowering the risk of ankylosis (8). In cases of major displacement and loss of functional occlusion, when a closed reduction is not possible, ORIF is indicated and the result would overcome the presumptive complications (29). To access the fractured area, different approaches are available and surgeons would decide upon a suitable approach, based on experience and personal taste. Some of these approaches are periauricular, submandibular, retromandibular antroparotid and retromandibular transparotid. The retromandibular antroparotid with a two centimeter incision under the ear lobule is utilized in this center. Postsurgical scaring is less evident in this approach and no entry to the parotid gland occurs, preventing complications such as salivary fistula (35).

\subsection{Endoscopic-assisted reduction and internal fixation}

ERIF is said to be embracing the benefits of both the closed and the open techniques. The resulting scar is very minor, no facial nerve damage is expected and a functional occlusion is ensured with anatomic reduction. An excellent visibility is achieved through the endoscope. This method is also swifter in comparison to other extraoral techniques (36). According to literature, it is said that by using the endoscope, a variety of methods are possible. (37-39), although an intraoral approach is most commonly used by the surgeons utilizing an endoscope (40, 41). This approach is also used in this center, and a small incision on the skin suffices the entry of the trocar. The majority of the subcondylar fractures can be managed by this method, however an ORIF procedure would be the treatment of choice in cases of significant displacements. Despite the preponderance and imperfections of the mentioned methods, the goal is achieving the premorbid and normal function of the patient with minimal damage. Pointing out the best procedure is certainly not easy assay and many factors influence the matter, so the aim of this review was to summarize the available methods, and their advantages and disadvantages, in order to help make the 
decision easier. Due to different techniques and materials and more importantly the position and kind of the subcondylar fracture, choosing the right treatment protocol is a challenge every time. Despite the many clinical researches available on management of condylar fractures, it still remains a matter of debate (36). The modern day surgical techniques such as the endoscope-assisted technology, reducing the morbidity rate, again raises the question of choosing either the open or closed treatment technique (42). The closed technique is continues to be the most commonly used for medium to large displacements (43). Retrospective and prospective studies in literature comparing open and closed treatments, report that the surgical procedure has no superiority to the closed technique as in function, range of motion, occlusion, contour, sensory or motional function retrieval. The most common complaint of patients after six months was chronic pain after the closed reduction and a noticeable scar after the surgical treatment $(22,44,45)$. M. Gupta et al. concluded that after both treatment protocols, the patients presented similar occlusion, retention of the reduced part's fixation, trismus index, mandibular movements and chewing sufficiency. The notable differences were the patient's discomfort during mandibular movements, chewing, swelling, neurogenic complications and parotid fistula on occasion after surgery (1). However several radiologic studies demonstrate a better anatomical reduction after the ORIF treatment $(19,45-49)$. The study of conservative treatment of 466 condylar fractures carried out by Zachariades et al., concluded that the closed technique is the treatment of choice for most of the subcondylar fractures, unless when there isn't a recoverable occlusion, severe displacement, loss of height of ramus or an edentate patient where the open reduction is indicated (50). Other ever growing studies however, emphasize on the benefits of surgery. Two prospective randomized, multi-center studies by Eckelt et al. (46) and Schneider et al. (48) mentioned that the two indicators for surgery are the condylar angle of $10-45^{\circ}$ and the loss of more than two millimeters of the ramus height. These studies also concluded that despite the surgical technique, anatomic reduction, mouth opening, lateral and forward movements of the mandible and the lower rate of pain and discomfort of the patients were considered beneficial in the ORIF group. The study by Lee JW et al., and AL-moraissi et al., are also in accordance with the latter argument $(51,52)$. However there are some studies about complications of open surgeries which indicate that permanent deformity and dysfunction after surgery is very rare (27), also the mandibular and condylar mobility is better $(29,30)$ and opening incisor pathway is much more normal (31) and also due to not decreasing the ramus height, less asymmetry is visible (28). Kokmueller et al. (36) in 2012 carried out a study to assimilate the endoscope-assisted transoral treatment and closed reduction of subcondylar fractures. Both closed reduction and the endoscopic surgery had acceptable results. Patients undergoing surgery had more complaints in the short run, but they were presented with fewer symptoms in long term follow ups. Patients with endoscopic treatment had better occlusion parameters both in early and late follow up sessions. It is mentioned several times in literature that the surgical complications of patients are far less, when treated transorally by the endoscopic-assisted method $(19,23,53,54)$. Authors using the endoscopic method to treat subcondylar fractures believe that a single intraoral incision would be sufficient to reduce a laterally displaced condyle. Even for lateral dislocations of the subcondylar area, an intraoral approach is suggested, due to the unperceptive scar, no matter how challenging it may be $(40,41)$. It is wise to emphasize on the short duration of this procedure also $(41)$, butfor the surgeons who are newly utilizing this method, there is probably much more time to perform the anatomic reduction and do the surgery than the conventional extraoral methods. But according to the learning curve that is considered for endoscopic treatment, this time will soon be decreased (55). For more complicated malocclusions and bigger dislocations however, the open technique is preferable.

\section{Conclusions}

Overall it is safe to declare that endoscopic surgery is certainly a good replacement for approaches through the skin, for subcondylar fractures. Avoiding the complications related to the traditional open technique such as the facial nerve damage, scarring and those related to the close technique such as the lengthened MMF, non-anatomical reduction and difficulties associated with mandibular movements, have deemed the endoscopic method a favorite among surgeons. With enhanced experience of the surgeons toward the endoscopic technique the controversies over the right treatment choice would slowly subside.

\section{Acknowledgments:}

This research received no specific grant from the government or any other funding agency in the public, commercial, or not-for-profit sectors.

\section{Conflict of Interest:}

There is no conflict of interest to be declared. 


\section{Authors' contributions:}

All authors contributed to this project and article equally. All authors read and approved the final manuscript.

\section{References:}

1) Gupta M, Iyer N, Das D, Nagaraj J. Analysis of different treatment protocols for fractures of condylar process of mandible. J Oral Maxillofac Surg. 2012; 70(1): 83-91. doi: 10.1016/j.joms.2011.02.009. PMID: 21549492.

2) Chrcanovic BR. Factors influencing the incidence of maxillofacial fractures. Oral Maxillofac Surg. 2012; 16(1): 3-17. doi: 10.1007/s10006-011-0280-y. PMID: 21656125.

3) Chrcanovic BR, Abreu MH, Freire - Maia B, Souza LN. Facial fractures in children and adolescents: a retrospective study of 3 years in a hospital in Belo Horizonte, Brazil. Dent Traumatol. 2010; 26(3): 262-70. doi: 10.1111/j.1600-9657.2010.00887.x. PMID: 20456472.

4) Chrcanovic BR, Freire-Maia B, Souza LN, Araújo VD, Abreu MH. Facial fractures: a 1 -year retrospective study in a hospital in Belo Horizonte. Braz Oral Res. 2004; 18(4): 322-8. doi: 10.1590/S180683242004000400009

5) Chrcanovic BR, Souza LN, Freire-Maia B, Abreu MH. Facial fractures in the elderly: a retrospective study in a hospital in Belo Horizonte, Brazil. J Trauma. 2010; 69(6): 73-8. doi: 10.1097/TA.0b013e3181cc847b. PMID: 20693928.

6) Chrcanovic BR, Abreu MH, Freire-Maia B, Souza LN. 1,454 mandibular fractures: a 3-year study in a hospital in Belo Horizonte, Brazil. J Craniomaxillofac Surg. 2012; 40(2): 116-23. doi: 10.1016/j.jcms.2011.03.012. PMID: 21458284.

7) Zandi M, Khayati A, Lamei A, Zarei H. Maxillofacial injuries in western Iran: a prospective study. Oral Maxillofac Surg. 2011; 15(4): 201-9. doi: 10.1007/s10006-011-0277-6. PMID: 21660436.

8) Hackenberg B, Lee C, Caterson EJ. Management of subcondylar mandible fractures in the adult patient. J Craniomaxillofac Surg. 2014; 25(1): 166-71. doi: 10.1097/SCS.0000000000000498. PMID: 24406572.

9) Jain G, Kumar S, Rana AS, Bansal V, Sharma P, Vikram A. Temporomandibular joint ankylosis: a review of 44 cases. Oral Maxillofac Surg. 2008; 12(2): 61-6. doi: 10.1007/s10006-008-0103-y. PMID: 18563457.

10) Kumar I, Singh V, Bhagol A, Goel M, Gandhi S. Supplemental maxillomandibular fixation with miniplate osteosynthesis-required or not? Oral Maxillofac Surg. 2011; 15(1): 27-30. doi: 10.1007/s10006-010-02296. PMID: 20411287.

11) Landes CA, Day K, Lipphardt R, Sader R. Closed versus open operative treatment of nondisplaced diacapitular (Class VI) fractures. J Oral Maxillofac Surg. 2008; 66(8): 1586-94. doi: 10.1016/j.joms.2007.06.668. PMID: 18634944.

12) Sanders B, McKelvy B, Adams D. Aseptic osteomyelitis and necrosis of the mandibular condylar head after intracapsular fracture. Oral Surg Oral Med Oral Pathol. 1977; 43(5): 665-70. doi: 10.1016/00304220(77)90048-2. PMID: 266145.

13) Fayazi S, Bayat M, Bayat-Movahed S, Sadr-Eshkevari P, Rashad A. Long-term outcome assessment of closed treatment of mandibular fractures. J Craniofac Surg. 2013; 24(3): 735-9. doi: 10.1097/SCS.0b013e3182801373. PMID: 23714869.

14) Choi SS, Rotaru H, Kim SG. Treatment of post-traumatic open bite by radiofrequency. Br J Oral Maxillofac Surg. 2007; 45(4): 311-3. doi: 10.1016/j.bjoms.2005.11.018.

15) Long X, Cheng Y, Li X, Li H, Hu S. Arteriovenous fistula after mandibular condylar fracture. J Oral Maxillofac Surg. 2004; 62(12): 1557-8. doi: 10.1016/j.joms.2004.01.028.

16) Yang WG, Chen CT, Tsay PK, Chen YR. Functional results of unilateral mandibular condylar process fractures after open and closed treatment. J Trauma. 2002; 52(3): 498-503. PMID: 11901326.

17) Baker AW, McMahon J, Moos KF. Current consensus on the management of fractures of the mandibular condyle: A method by questionnaire. Int J Oral Maxillofac Surg. 1998; 27(4): 258-66. PMID: 9698171.

18) Haug RH, Brandt MT. Closed reduction, open reduction, and endoscopic assistance: current thoughts on the management of mandibular condyle fractures. Plast Reconstr Surg. 2007; 120(7-2): 90-102. doi: 10.1097/01.prs.0000260730.43870.1b. PMID: 18090732.

19) Danda AK, Muthusekhar MR, Narayanan V, Baig MF, Siddareddi A. Open versus closed treatment of unilateral subcondylar and condylar neck fractures: a prospective, randomized clinical study. J Oral Maxillofac Surg. 2010; 68(6): 1238-41. doi: 10.1016/j.joms.2009.09.042. PMID: 20303209.

20) Ellis E 3rd, Throckmorton GS. Bite forces after open or closed treatment of mandibular condylar process fractures. J Oral Maxillofac Surg. 2001; 59(4): 389-95. doi: 10.1053/joms.2001.21873. PMID: 11289168. 
21) Santler G, Kärcher H, Ruda C, Köle E. Fractures of the condylar process: surgical versus nonsurgical treatment. J Oral Maxillofac Surg. 1999; 57(4): 392-7. doi: 10.1016/S0278-2391(99)90276-8. PMID: 10199490.

22) Haug RH, Assael LA. Outcomes of open versus closed treatment of mandibular subcondylar fractures. J Oral Maxillofac Surg. 2001; 59(4): 370-5. doi: 10.1053/joms.2001.21868. PMID: 11289165.

23) Schmelzeisen R, Cienfuegos-Monroy R, Schön R, Chen CT, Cunningham L Jr, Goldhahn S. Patient benefit from endoscopically assisted fixation of condylar neck fractures-a randomized controlled trial. J Oral Maxillofac Surg. 2009; 67(1): 147-58. doi: 10.1016/j.joms.2008.09.019. PMID: 19070761.

24) Ferretti C, Bryant R, Becker P, Lawrence C. Temporomandibular joint morphology following posttraumatic ankylosis in 26 patients. Int J Oral Maxillofac Surg. 2005; 34(4): 376-81. doi: 10.1016/j.ijom.2004.09.003. PMID: 16053845.

25) Arakeri G, Kusanale A, Zaki GA, Brennan PA. Pathogenesis of post-traumatic ankylosis of the temporomandibular joint: a critical review. Br J Oral Maxillofac Surg. 2012; 50(1): 8-12. doi: 10.1016/j.bjoms.2010.09.012. PMID: 20970228.

26) Meng FW, Zhao JL, Hu KJ, Liu YP. A new hypothesis of mechanisms of traumatic ankylosis of temporomandibular joint. Med Hypotheses. 2009; 73(1): 92-3. doi: 10.1016/j.mehy.2009.01.024. PMID: 19261390.

27) Ellis E 3rd, McFadden D, Simon P, Throckmorton G. Surgical complications with open treatment of mandibular condylar process fractures. J Oral Maxillofac Surg. 2000; 58(9): 950-8. doi: 10.1053/joms.2000.8734. PMID: 10981974.

28) Ellis E 3rd, Throckmorton G. Facial symmetry after closed and open treatment of fractures of the mandibular condylar process. J Oral Maxillofac Surg. 2000; 58(7): 719-28. doi: 10.1053/joms.2000.7253. PMID: 10883686.

29) Palmieri C, Ellis E 3rd, Throckmorton G. Mandibular motion after closed and open treatment of unilateral mandibular condylar process fractures. J Oral Maxillofac Surg. 1999; 57(7): 764-75. doi: 10.1016/S02782391(99)90810-8. PMID: 10416622.

30) Throckmorton GS, Ellis E 3rd. Recovery of mandibular motion after closed and open treatment of unilateral mandibular condylar process fractures. Int J Oral Maxillofac Surg. 2000; 29(6): 421-7. doi: 10.1034/j.1399-0020.2000.290605.x. PMID: 11202321.

31) Throckmorton GS, Ellis E 3rd, Hayasaki H. Masticatory motion after surgical or nonsurgical treatment for unilateral fractures of the mandibular condylar process. J Oral Maxillofac Surg. 2004; 62(2): 127-38. doi: 10.1016/j.joms.2003.01.003. PMID: 14762743.

32) Kallela I, Söderholm AL, Paukku P, Lindqvist C. Lag-screw osteosynthesis of mandibular condyle fractures: a clinical and radiological study. J Oral Maxillofac Surg. 1995; 53(12): 1397-404. doi: 10.1016/0278-2391(95)90663-0.

33) Manisali M, Amin M, Aghabeigi B, Newman L. Retromandibular approach to the mandibular condyle: a clinical and cadaveric study. Int J Oral Maxillofac Surg. 2003; 32(3): 253-6. doi: 10.1054/ijom.2002.0270. PMID: 12767870.

34) Tasanen A, Lamberg MA. Transosseous wiring in the treatment of condylar fractures of the mandible. J Oral Maxillofac Surg. 1976; 4(4): 200-6. doi: 10.1016/S0301-0503(76)80036-7. PMID: 1070500.

35) Biglioli F, Colletti G. Mini-retromandibular approach to condylar fractures. J Craniomaxillofac Surg. 2008; 36(7): 378-83. doi: 10.1016/j.jcms.2008.05.001. PMID: 18599302.

36) Kokemueller H, Konstantinovic VS, Barth EL, Goldhahn S, von See C, Tavassol F, et al. Endoscopeassisted transoral reduction and internal fixation versus closed treatment of mandibular condylar process fractures-a prospective double-center study. J Oral Maxillofac Surg. 2012; 70(2): 384-95. doi: 10.1016/j.joms.2011.02.035. PMID: 21664746.

37) Kellman RM. Endoscopic approach to subcondylar mandible fractures. Facial plast surg. 2004; 20(3): 23947. doi: 10.1055/s-2004-861780. PMID: 15643597.

38) Mueller R. Endoscopic treatment of facial fractures. Facial Plast Surg. 2008; 24(1): 78-91. doi: 10.1055/s2008-1037452. PMID: 18286437.

39) Troulis MJ. Endoscopic open reduction and internal rigid fixation of subcondylar fractures. J Oral Maxillofac Surg. 2004; 62(10): 1269-71. doi: 10.1016/j.joms.2004.04.016.

40) Lo J, Cheung LK. Endoscopic-assisted rigid fixation of condylar fracture: a technical note. J Oral Maxillofac Surg. 2006; 64(9): 1443-6. doi: 10.1016/j.joms.2006.05.029. 
41) Schön R, Gutwald R, Schramm A, Gellrich NC, Schmelzeisen R. Endoscopy-assisted open treatment of condylar fractures of the mandible: extraoral vs intraoral approach. Int J Oral Maxillofac Surg. 2002; 31(3): 237-43. doi: 10.1054/ijom.2001.0213. PMID: 12190127.

42) Ellis E 3rd. Method to determine when open treatment of condylar process fractures is not necessary. J Oral Maxillofac Surg. 2009; 67(8): 1685-90. doi: 10.1016/j.joms.2009.03.062. PMID: 19615583.

43) Walker RV. Condylar fractures: nonsurgical management. J Oral Maxillofac Surg. 1994; 52(11): 1185-8. doi: 10.1016/0278-2391(94)90542-8. PMID: 7965314.

44) Hidding J, Wolf R, Pingel D. Surgical versus non-surgical treatment of fractures of the articular process of the mandible. J Craniomaxillofac Surg. 1992; 20(8): 345-7. doi: 10.1016/S1010-5182(05)80363-4. PMID: 1464684.

45) Konstantinović VS, Dimitrijević B. Surgical versus conservative treatment of unilateral condylar process fractures: clinical and radiographic evaluation of 80 patients. J Oral Maxillofac Surg. 1992; 50(4): 349-52. doi: 10.1016/0278-2391(92)90395-G. PMID: 1545289.

46) Eckelt U, Schneider M, Erasmus F, Gerlach KL, Kuhlisch E, Loukota R, et al. Open versus closed treatment of fractures of the mandibular condylar process-a prospective randomized multi-centre study. J Craniomaxillofac Surg. 2006; 34(5): 306-14. doi: 10.1016/j.jcms.2006.03.003. PMID: 16781159.

47) Hayward JR, Scott RF. Fractures of the mandibular condyle. J Oral Maxillofac Surg. 1993; 51(1): 57-61. doi: 10.1016/S0278-2391(10)80391-X. PMID: 8419574.

48) Schneider M, Erasmus F, Gerlach KL, Kuhlisch E, Loukota RA, Rasse M, et al. Open reduction and internal fixation versus closed treatment and mandibulomaxillary fixation of fractures of the mandibular condylar process: a randomized, prospective, multicenter study with special evaluation of fracture level. J Oral Maxillofac Surg. 2008; 66(12): 2537-44. doi: 10.1016/j.joms.2008.06.107. PMID: 19022134.

49) Takenoshita $Y$, Ishibashi $H$, Oka $M$. Comparison of functional recovery after nonsurgical and surgical treatment of condylar fractures. J Oral Maxillofac Surg. 1990; 48(11): 1191-5. doi: 10.1016/02782391(90)90535-A. PMID: 2213313.

50) Zachariades N, Mezitis M, Mourouzis C, Papadakis D, Spanou A. Fractures of the mandibular condyle: a review of 466 cases. Literature review, reflections on treatment and proposals. J Craniomaxillofac Surg. 2006; 34(7): 421-32. doi: 10.1016/j.jcms.2006.07.854. PMID: 17055280.

51) Al-Moraissi EA, Ellis E 3rd. Surgical treatment of adult mandibular condylar fractures provides better outcomes than closed treatment: a systematic review and meta-analysis. J Oral Maxillofac Surg. 2015; 73(3): 482-93. doi: 10.1016/j.joms.2014.09.027. PMID: 25577459.

52) Lee JW, Lee YC, Kuo YL. Reappraisal of the surgical strategy in treatment of mandibular condylar fractures. Plast Reconstr Surg. 2010; 125(2): 609-19. doi: 10.1097/PRS.0b013e3181c82ff0. PMID: 19910844.

53) Schön R, Fakler O, Gellrich NC, Schmelzeisen R. Five-year experience with the transoral endoscopically assisted treatment of displaced condylar mandible fractures. Plast Reconstr Surg. 2005; 116(1): 44-50. doi: 10.1097/01.PRS.0000169690.78547.0C. PMID: 15988246.

54) Veras RB, Kriwalsky MS, Eckert AW, Schubert J, Maurer P. Long-term outcomes after treatment of condylar fracture by intraoral access: a functional and radiologic assessment. J Oral Maxillofac Surg. 2007; 65(8): 1470-6. doi: 10.1016/j.joms.2006.07.016. PMID: 17656270.

55) Loukota RA. Endoscopically assisted reduction and fixation of condylar neck/base fractures-The learning curve. Br J Oral Maxillofac Surg. 2006; 44(6): 480-1. doi: 10.1016/j.bjoms.2005.11.019. 